\title{
O TALLER DE ENSEÑANZA DE FÍSICA: INOVAÇÕES E PRESSUPOSTOS DE UMA PROPOSTA UNIVERSITÁRIA DE APRENDIZAGEM COLABORATIVA
}

\section{THE TALLER DE ENSEÑANZA DE FÍSICA: INNOVATIONS AND ASSUMPTION OF A PROJECT OF COLLABORATIVE LEARNING AT THE COLLEGE LEVEL}

\author{
Silvina Cordero \\ Universidade de La Plata
}

\section{Resumo:}

Neste artigo apresentaremos uma descrição do Taller de Enseñanza de Física (TEF) proposta pedagógica universitária inovadora. Partindo de localizar ao TEF no contexto universitário argentino de ensino de Física, descreveremos a experiência na base das suas inovações mais destacadas e comentaremos algumas singularidades da equipe docente e suas formas de trabalho. No final, tentaremos delinear pressupostos da proposta, que fazem dela um caso singular, mas que podem ser compartilhados por muitos outros docentes.

Palavras chave: Ensino de Física, Ensino de Ciências no nível superior, currículo de ciências

\section{Abstract:}

In this paper, we present a description of the Taller de Enseñanza de Física (TEF), an innovative project for teaching at the college level. First, we situate TEF in the Argentinean context of college education in Physics, then we describe the experience considering the most outstanding innovations, and we comment on some of the singularities of the teaching team as well as its forms of working. Finally, we try to outline the assumptions of the project, which made it a singular case, but can be shared with many other professors.

Key-words: Physics teaching, Science teaching at the college level, science curriculum 


\section{INTRODUÇÃO:}

Esse é um texto construído na base de muitos textos. Textos próprios e alheios, referentes a uma proposta universitária de ensino de Física, o Taller de Enseñanza de Física $^{1}$ (TEF). Esses textos foram produzidos por docentes e pesquisadores a partir da sua preocupação por explicitar e sistematizar seu trabalho, sua maneira de ensinar física na universidade, e os fundamentos da sua ação. E também por pesquisar acerca de diversos aspectos da proposta e sua implementação. Pensamos que essa característica nos permite inserir inicialmente aos docentes do TEF no paradigma do "professor reflexivo" (Schön, 1995; Zeichner, 1993; Salinas Fernández, 1994). Falamos em reflexão como "forma de reflexividade na qual o sujeito toma sua própria ação e seus modos de funcionar mentalmente como objeto de sua observação e de sua análise e tenta compreender seu modo de pensar e de agir" (Queiroz, 2000:14).

Consideramos que o TEF constitui uma proposta didática inovadora. Libedinsky (2001:60. Tradução nossa) aponta: "As inovações didáticas emergentes são propostas de ensino geradas pelos docentes, caracterizadas pela ruptura e oposição às práticas vigentes consolidadas, profundamente vinculadas ao conteúdo curricular disciplinar, e que atendem tanto aos interesses culturais dos docentes que as planejam e lideram, quanto aos interesses culturais dos estudantes". Vale então iniciar esclarecendo que neste trabalho descreveremos uma experiência de educação em física na universidade, gerada em 1985 por um docente e um grupo de alunos, que procuravam mudar sua forma de ensinar e aprender ciência, entre outras coisas.

A descrição de uma inovação na universidade aponta para diversos propósitos: por um lado, interessa-nos valorizar o trabalho consciente, silencioso e continuado da equipe de professores que gerou e mantêm esta inovação; por outro lado, porque consideramos que sistematizar e analisar a própria prática de ensino constitui um caminho para sua melhora; e finalmente, porque desejamos assinalar percursos possíveis para outros docentes universitários ou não, interessados em mudar suas práticas e ambientes educativos.

No início, apresentaremos algumas das características básicas do TEF como proposta pedagógica. Em segundo lugar, localizaremos ao TEF no contexto universitário argentino em geral, e do ensino de Física em particular. A seguir descreveremos a experiência na base das suas inovações mais destacadas e comentaremos algumas singularidades da equipe docente e suas formas de trabalho. No final, tentaremos delinhar pressupostos da proposta, que fazem dela um caso singular, mas que podem ser compartilhados por muitos outros docentes.

\section{Apresentação do TEF: Características básicas}

Os estudantes dos Bacharelados em Biologia e Geologia da Faculdade de Ciências Naturais da Universidade Nacional de La Plata, Argentina, devem cursar, como parte da sua formação, uma disciplina obrigatória anual denominada "Física Geral" na Faculdade de Ciências Exatas (no $2^{\circ}$ ano do currículo).

Desde 1985, esta matéria tem duas modalidades de curso $^{2}$, com diferentes características gerais:

a) Modalidade Convencional:

\footnotetext{
${ }^{1}$ Oficina de Ensino de Física.

${ }^{2}$ Em alguns anos houveram três alternativas de curso.
} 
- 3 horas semanais de Aulas Práticas obrigatórias.

- 3 horas semanais de Aulas Teóricas não obrigatórias.

- 2 Provas Parciais escritas (uma em cada quatrimestre) que incluem resolução de problemas "tipo".

- 1 Exame Final (em geral oral, às vezes com uma etapa inicial escrita).

b) Modalidade TEF:

- 6 horas semanais de Curso Teórico-Prático obrigatório.

- 3 Avaliações Parciais (cuja forma pode variar ano a ano, já que é discutida com os alunos. Em geral, a primeira e a segunda avaliações consistem em provas escritas de resolução de problemas, realizadas grupalmente com defesa oral individual; a terceira é similar mas pode envolver, para aqueles alunos que voluntariamente a escolheram, a realização grupal de trabalhos de investigação, com defesa oral individual ).

- 1 Exame Final (em geral oral, às vezes com uma etapa inicial escrita).

O Programa de Conteúdos a desenvolver nas duas modalidades da matéria é diferente, mas tem conteúdos básicos comuns. A prova final é em geral a mesma, com iguais conteúdos para ambas modalidades, mas para os alunos do TEF que decidem completar os trabalhos de investigação da $3^{\circ}$ avaliação parcial, pode também incluir a apresentação de:

- PETIC: pequeno trabalho de investigação criativo

- TRAP: trabalho de aplicação

- TREX: trabalho de "extensão" (vale dizer a elaboração de uma proposta de extensão

à comunidade referente à aplicação de conhecimentos físicos em problemas biológicos ou geológicos)

Em todos os casos acima, o trabalho é realizado em grupo de até quatro alunos e na prova final apresentado em uma defesa oral individual.

Ano a ano, devido à flutuação de ingressados na Faculdade de Ciências Naturais, tem variado o número de alunos que cursa a disciplina nas duas modalidades. Mas a média de alunos que escolhe o curso do TEF, nos últimos anos, encontra-se na casa dos 200 alunos. $O$ processo de escolha da modalidade desenvolve-se durante o primeiro mês do curso, quando os alunos têm a liberdade de assistir às aulas das duas opções, e avaliar qual será a mais adequada às suas características pessoais e necessidades.

O TEF está institucionalmente vinculado ao Departamento de Física da Faculdade de Ciências Exatas. Uma parte de seus professores pertence a esse Departamento e outra parte à Faculdade de Ciências Naturais.

\section{O contexto institucional: a Universidade Nacional de La Plata}

A Universidade, como todos os outros níveis educativos na Argentina, sofreu na década de 1990 turbulentos processos de mudança. Nos últimos anos aprovaram-se a Lei Federal de Educação (1994) e a Lei de Educação Superior (1995); implantaram-se sistemas de promoção e avaliação permanente da produção científica dos docentes universitários; instauraram-se, não pouco conflitivamente, mecanismos de avaliação institucional interna e externa das Universidades; elaboraram-se os "Conteúdos Básicos Comuns" (para o nível 
obrigatório de escolaridade); e se desenvolveram novos sistemas de formação contínua para docentes da "Educação Geral Básica" e do "Polimodal", implementados às pressas e muitas vezes descontinuados, nos quais participam ativamente as Universidades. Muitas outras modificações estão em andamento, entre elas são discutidas alternativas de pagamento dos cursos de graduação, como a fixação de taxas para os alunos ou o estabelecimento de impostos diferenciados para os pais dos universitários. Este contexto torna inevitável, e ao mesmo tempo complexa, a análise das práticas universitárias de ensino e aprendizagem.

Nos estudos sobre a Universidade argentina, fala-se freqüentemente de um sistema "em crise", e propõe-se como necessário afrontar o desafio de produzir uma profunda e significativa transformação. Mas não deixam de ser consideradas as limitações impostas pelas restrições econômicas que, possivelmente, vão se manter por um longo tempo, devido ao estabelecimento de um novo modelo de relação entre Universidade e Estado, tendente à "desresponsabilização por parte deste último de sua obrigação de manutenção econômica da educação superior" (Puiggrós, 1993:14. Tradução nossa).

A Universidade Nacional de La Plata, uma das Universidades mais antigas do país (criada no final do século XIX), não escapa dessa caracterização geral. É considerada uma instituição "tradicional"; heterogênea em relação aos tipos e tamanhos das unidades acadêmicas que a compõem ${ }^{3}$; com áreas de investigação muito desenvolvidas (as Ciências Exatas e Naturais, fundamentalmente), que por sua vez são as que possuem os cursos de pós-graduação mais consolidados; e com outras áreas, como as das Ciências Sociais, com maior desenvolvimento do ensino de graduação, mas com estruturas de pesquisa apenas incipientes. Por outro lado, em relação à função "ensino", pertence ao rol das Universidades consideradas "grandes" na Argentina, com uma população de quase 50.000 estudantes (47.845 segundo o Censo de Estudantes Universitários, 1994), fazendo-se responsável por aproximadamente $10 \%$ da demanda de ingressos universitários do país, e de uma percentagem similar do total dos egressos. Isso tem como conseqüência, para a maioria dos cursos, turmas numerosíssimas e sérias dificuldades tanto para o desenvolvimento da aprendizagem, quanto para o trabalho docente.

O TEF é uma experiência singular neste contexto, pela sua continuidade e o que poderíamos considerar seu sucesso. Teve seu inicio em 1985, quando a democratização política nacional manifestou-se na Universidade, e possibilitou a criação de novos espaços de reflexão, inovação pedagógica e participação. Continua desenvolvendo-se, ao abrigo do Departamento de Física da Faculdade de Ciências Exatas, uma das unidades mais "tradicionais" da nossa Universidade (criado como instituto de pesquisa em 1905).

O grupo de docentes responsáveis pela implantação do TEF foi consolidando, desde sua origem, uma postura em relação ao papel social que cabe à Universidade. Sustenta-se, dentro do marco teórico geral da proposta e funcionando como "idéias-força" ${ }^{\text {, }}$, que a Universidade não pode se isolar dos problemas da sociedade. Para isso, alunos e professores devem alcançar um nível de compromisso que lhes permita atuar nela em um sentido de transformação social. Um dos propósitos da experiência é desenvolver um trabalho de modificação do próprio âmbito universitário visando à ampliação de projetos inovadores, a partir do

\footnotetext{
${ }^{3}$ Abarca todos os níveis de ensino, já que possui desde uma creche e jardim de infância, até Cursos de Pós-Graduação em diversas disciplinas.

${ }^{4}$ Extraído de um trabalho de sistematização e análise da experiência, realizado pelos docentes do TEF e outros pesquisadores, sob a direção da Prof. Hilda Weissmann entre os anos 1991-1992 (Weissmann et al, 1992).
} 
pressuposto de que, enquanto a Universidade é parte integrante do todo social, atuar dentro dela é também atuar para a transformação da sociedade partindo das condições existentes. Nesse aspecto, a proposta tem dado origem a grupos, com princípios educativos baseados na autogestão, que desenvolveram experiências inovadoras em diversas áreas (Oficinas de Pesquisa, "Biologazo", "Interáreas", Cooperativa de Trabalho, etc. ${ }^{5}$ ).

É neste contexto, então, que a experiência objetiva: o preparo do estudante dos pontos de vista intelectual e ético, promovendo a sua inserção crítica e ativa na sociedade e no seu futuro papel acadêmico e/ou profissional. Isso significa, para os docentes do TEF, não apenas a apropriação de conhecimentos, mas também a formação de atitudes, tais como a autonomia, o pensamento crítico, a solidariedade, entre outras ${ }^{6}$. Considera-se necessária portanto a criação de um clima de aula favorável para propiciar mudanças no estudante, tendendo a que alcance a sua autonomia e realização pessoal.

\section{O ensino de física a nível universitário: algumas considerações}

Tradicionalmente, o ensino de Física Geral, no nível universitário, caracteriza-se pelo desenvolvimento de programas de conteúdos conceituais similares para todos os cursos que incluem essa disciplina em seu currículo. Apesar das grandes diferenças em relação ao perfil de aluno (portanto a interesses), à organização curricular dos cursos, e ao perfil de inserção profissional dos formados em cursos de graduação como Engenharia, Arquitetura, Biologia, Agronomia, Farmácia, Design Industrial, etc., a Física Geral que é oferecida dentro desses cursos, não tem merecido, em geral, adaptação às diversas especialidades. Esse problema, a nosso ver, tem origem, em parte, na escassa ou nenhuma relação acadêmica inter e intrafaculdades (a estrutura departamental, que existe na maioria das Faculdades, não garante uma real comunicação entre docentes para o intercâmbio referente aos conteúdos ou às estratégias docentes).

A metodologia de ensino tampouco mostra grandes variações, caracterizando-se em geral pelo desenvolvimento de: aulas teóricas magistrais; resolução de roteiros de trabalhos práticos e de guias de problemas similares; realização de algumas experiências de laboratório estritamente pautadas e não aplicadas à especialidade; e avaliação por resolução individual de problemas (Weissmann et al, 1992).

A partir da sua criação em 1985, o TEF objetivou, entre outros aspectos, a superação dessa uniformidade. Foi nesse caminho que desenvolveu uma série de inovações, que apresentaremos a seguir.

\section{As inovações próprias do TEF}

As inovações implementadas no TEF abarcaram numerosos e diversos aspectos da proposta: estratégias de ensino e aprendizagem; conteúdos; tipos de interação entre alunos e entre docentes e alunos; avaliação; papel, forma de trabalho e capacitação dos professores;

\footnotetext{
${ }^{5}$ As Oficinas de Pesquisa foram espaços não curriculares para o desenvolvimento de pequenos projetos de investigação interdisciplinar, elaborados por alunos e docentes; o Biologazo foi um grupo de extensão universitária, constituído por alunos e ex-alunos do TEF, que levou a cabo atividades de divulgação científica e educação ambiental; Interáreas foi uma agrupação política estudantil, que ganhou as eleições e participou do co-governo da Faculdade de Ciências Naturais e da Universidade entre 1987/88; a Cooperativa de Trabalho foi uma iniciativa de docentes e ex-alunos do TEF interessados em realizar trabalhos de educação ambiental por fora do âmbito universitário.

${ }^{6}$ Essa idéia parece coerente com a proposta de Krasilchik (1992: 5): “...é necessário preparar profissionais que tenham, além de uma sólida base de conhecimento, criatividade para encontrar soluções próprias e assumir compromisso com o desenvolvimento nacional."
} 
atividades de extensão e de pesquisa. A seguir, listaremos as inovações mais destacadas a fim de descrever sinteticamente a experiência ${ }^{7}$ :

X Oferecer aos estudantes a oportunidade de optar pela metodologia de trabalho que melhor se adapte a seus interesses, estilo de aprendizagem, nível de compromisso, etc.

No início do curso, durante o primeiro mês, os estudantes podem escolher de qual modalidade de ensino eles querem participar. Como comentamos acima, são oferecidas duas modalidades, com características e exigências diferentes, mas que abordam conteúdos mínimos similares e que têm igual validade institucional. Os alunos aprovados em qualquer das duas modalidades são logo examinados por uma banca de professores do Departamento de Física, em geral através dos mesmos procedimentos metodológicos.

X Foco na explicitação e tomada de consciência dos estudantes a respeito das noções alternativas como ponto de partida para a construção coletiva do novo conhecimento, dos pontos de vista conceitual, metodológico e atitudinal.

Em relação a esse aspecto, comenta-se em diversos artigos um "modelo de seqüência de ensino":

- "Explicitação dos esquemas de conhecimento que o estudante construiu em experiências anteriores. Isto permite partir de uma linguagem comum ao grupo, que coloca os alunos e seus conhecimentos como 'eixos' da aula. A partir dessa base o docente ajusta as atividades e o aluno pode reconhecer seu processo de evolução conceitua l e autoavaliar-se.

- Apresentação de experimentos, demonstrações, problemas, exemplos contraintuitivos, etc. objetivando criar um conflito cognitivo entre a estrutura prévia do aluno e as anomalias que aí surgem. O resultado esperado é provocar insatisfação a respeito de seu esquema conceitual a fim de motivar para que se resolva o conflito, gerando assim uma predisposição maior para a aprendizagem significativa.

- Apresentação das concepções do saber científico utilizando diversos modos de representação (verbal, matemático, gráfico).

- Desenvolvimento de estratégias de avaliação que permitem acompanhar o processo de evolução conceitual, a fim de realizar os ajustes necessários. Como parte dessas estratégias propõe-se a aplicação do conhecimento a novas situações e novos conteúdos e a realização de um 'redondeio' ou síntese ao finalizar cada unidade conceitual." (Cordero et al., 1996:20. Tradução nossa)

Esse modelo teórico de seqüência, construído a partir da análise da prática desenvolvida no TEF, não é aplicado estritamente em todos os seus pontos para todos os temas do currículo. No entanto, é interessante destacar como se aproxima da seqüência proposta por Driver \& Oldham (1997:128) para o ensino construtivista, que compreende cinco fases: orientação, elicitação, reestruturação, aplicação e revisão.

\footnotetext{
${ }^{7}$ Ver nota 4.
} 
Nos últimos anos foi revisado o objetivo de promover o conflito cognitivo, propondo-se os docentes do TEF uma visão da aprendizagem como evolução conceitual (Moreira, 1996) ou como integração hierárquica (Pozo, 2000).

X Adequação da metodologia de desenvolvimento das aulas teóricas à
modalidade do TEF. Uma característica importante das aulas do TEF é a superação da compartimentalização, habitual na universidade argentina, entre aulas teóricas e práticas. No TEF não existe nem um horário nem um dia fixo para a apresentação teórica de conteúdos. As exposições teóricas são incluídas no planejamento das aulas, no momento e com a duração que o tema, o "clima" de aula, as dificuldades dos alunos, e outras variáveis consideradas, merecem. Se desenvolvem também por meio de estratégias peculiares; dentre elas, o "teórico dialogado", quer dizer, a exposição teórica realizada por dois ou mais professores conjuntamente (Dumrauf et al, 2000).

\section{Desenvolvimento de uma dinâmica pedagógica espiralada para a apresentação dos novos conhecimentos.}

Uma característica interessante, em relação às estratégias de ensino, é a apresentação repetida dos novos conhecimentos, em diferentes instâncias, através de diversas técnicas e por distintos sujeitos. Isto quer dizer que o conteúdo exposto em uma apresentação teórica por um docente, é retomado logo na resolução de problemas ou realização de experiências em grupos, e re-explicado aos alunos nessa situação, por outros docentes responsáveis pela coordenação grupal; geralmente é reformulado depois, em uma nova discussão coordenada entre a turma toda e outros docentes, a partir dos resultados dos problemas ou experiências ("redondeio"); e muitas vezes, é trabalhado também independentemente em aulas especiais, com grupos de alunos que apresentam dificuldades para a sua compreensão. Essas sucessivas aproximações dos novos conteúdos configuram uma dinâmica pedagógica específica, que poderia ser caracterizada pela imagem de uma espiral, na qual se oferecem aos alunos diversas oportunidades para a aquisição dos novos significados.

\section{Elaboração de estratégias de ensino que tendem a promover, de maneira planejada, a participação ativa do estudante, o raciocínio, e o desenvolvimento de um pensamento crítico e criativo.}

As estratégias de ensino utilizadas no TEF têm sido objeto de vários trabalhos de sistematização. Em um deles, por exemplo, comentávamos as estratégias utilizadas em relação ao objetivo de:

“...aplicar os conhecimentos que estão aprendendo e avaliar o processo de evolução conceitual:

- Guia de trabalhos práticos (inclui problemas modelizados com sistema de estudo definido e que admitem só uma resposta e problemas modelizados abertos, nos quais deve ser definido o sistema de estudo e as condições iniciais): resolução em pequenos grupos, depois um grupo expõe para a turma. 
- Exercícios de aplicação (problemas vinculados com fenômenos do contexto, não modelizados, sem sistema definido e que admitem mais de uma resposta): resolução em pequenos grupos, depois um grupo expõe aos outros integrantes da turma." (Cordero et al, 1996: 23. Tradução nossa).

\section{X Ênfase na interação grupal colaborativa durante o processo de aprendizado.} Outra característica relevante do TEF é a explícita valorização do trabalho grupal, como base das estratégias de ensino da Física no nível universitário - expressa em numerosas produções analíticas de seus integrantes (Ivancich et al, 1991; Ivancich et al, 1993; Melgarejo et al, 1996). Tal característica nos permite definir a proposta do TEF que, fomentando a organização dos alunos a partir de estruturas cooperativas, pretende que as atividades sejam elaboradas e realizadas em conjunto. Essa proposta tem ainda a finalidade de que todos os membros do grupo consigam realizar coletivamente o objetivo pretendido. Em uma pesquisa recente (Cordero, 1999) abordamos um conjunto de questões a esse respeito, quais foram:

- Quais as características das interações entre alunos de Biologia e Geologia participantes do TEF?

- É possível identificar padrões de colaboração entre eles?

- Existem variações nas dinâmicas grupais em função das tarefas propostas?

Além disso tentamos verificar se a proposta "teórica" de funcionamento colaborativo, sustentada pelos docentes do TEF, se manifestava no interior das dinâmicas grupais dos alunos.

Como resultado do estudo reconstruímos processos sociais e cognitivos vivenciados pelos alunos de um grupo focal durante a abordagem do tema Termodinâmica. Nesse sentido cada episódio - dos quatro escolhidos para aprofundar a análise- teve características singulares. Mas também observamos algumas recorrências relevantes nessa reconstrução. A análise dos propôsitos das interações verbais permitiu-nos identificar numerosos raciocínios nas conversas grupais. Esses raciocínios evidenciaram, no nosso entendimento, a consecução de aprendizagem conceitual relativa à Termodinâmica do equilíbrio e do não equilíbrio. Do ponto de vista cognitivo, detectamos a existência de alguns conflitos (sócio)cognitivos entre alguns alunos nos episódios analisados. Consideramos essas situações como espaços de questionamento, relativização e mudança nas interpretações dos alunos sobre os processos e fenômenos termodinâmicos. Finalmente, compreendendo a dimensão social das interações grupais, percebemos a alternância de períodos de colaboração entre os membros do grupo e período(s) de domínio de um membro sobre a dinâmica grupal. Interpretamos essa alternância como movimentos de re-distribuição/reorientação do poder e do status no grupo, que evidenciaram a intercambiabilidade dos papéis no funcionamento grupal.

Chegamos finalmente a uma caracterização de processos grupais nas aulas do TEF, na qual integramos:

- a configuração cooperativa do grupo focal, com relativa rotatividade dos papéis, inferida a partir das interações entre alunos, atendendo às dimensões lingüística, cognitiva e social; 
- a concepção da tarefa como reguladora das dinâmicas grupais; e

- a consideração da particularidade do contexto pedagógico, que constitui um tipo de regulação institucional dos processos.

O TEF constitui portanto, ao nosso ver, uma proposta geradora de determinadas configurações nas interações entre alunos, de modo que fortalece a "grupalidade" (Souto, 1993) - aqui entendida como o potencial do grupo para se constituir enquanto tal, para além de um agregado de indivíduos.

\section{Preocupação por ampliar o alcance dos conteúdos a ensinar, incluindo o ensino de procedimentos e atitudes.}

Habitualmente são planejadas e realizadas atividades orientadas para promover o aprendizado de diversos procedimentos, como por exemplo, os relacionados à particular imagem da metodologia científica que os docentes do TEF possuem (Cappannini et al, 1996; Dumrauf, 1997; Dumrauf et al, 2000; e Dumrauf, 2001). As atitudes de docentes e alunos também são objeto de análise nas reuniões de planejamento, e formulam-se atividades de sala de aula que objetivam: revisar as atitudes apreendidas nos contextos educativos mais tradicionais e promover as atitudes desejáveis para o bom desenvolvimento da proposta e para obter a formação científica procurada, entre elas a participação, o respeito pelas opiniões dos outros, o compromisso, a responsabilidade, a rigorosidade, a curiosidade, a autocrítica, a predisposição para a dúvida, a aceptação do erro como parte do processo de aprendizado, etc (Cappannini et al, 1994).

Outra via de ensino de atitudes e procedimentos relaciona-se com uma estratégia desenvolvida pelos professores ao momento de ser solicitada sua ajuda ou correção por parte dos alunos. Foge-se da resposta direta que, para os docentes do TEF, supõe partir de um critério de autoridade e de uma visão arbitrária do conhecimento. Opta-se pela formulação de perguntas que orientem o raciocínio dos alunos ou evidenciem, do ponto de vista da disciplina, a causa do erro.

\section{Escolha e contextualização dos conteúdos da Física nas problemáticas biológicas e geológicas.}

Nestes 16 anos de existência, os docentes do TEF têm mudado o Programa de Conteúdos, com o fim, entre outros, de adaptá-lo às necessidades e os interesses dos estudantes de Biologia e Geologia. Isso significou um processo de avaliação contínua dos critérios de: escolha, seqüênciação e organização; e a realização de ajustes e negociações a cada ano.

Considera-se que, pela sua duração, o curso é incapaz de oferecer todos os conteúdos da Física que um egresso de Ciências Naturais vai precisar na sua prática profissional. Esses conteúdos são em geral muito específicos e diferem de acordo o curso e a área de trabalho. Portanto, o fundamento para a escolha e seqüênciação vem sendo introduzir o aluno no conhecimento da Física através da aprendizagem de alguns conceitos básicos e procedimentos da disciplina. Também pretende-se que o aluno 
compreenda a necessidade de usar ferramentas matemáticas para o estudo da Física, por sua vez necessária nos estudos biológicos e geológicos. Partindo desta base, os critérios de escolha e seqüênciação são de tipo epistemológico e pedagógico. $\mathrm{Na}$ Tabela I apresentamos as unidades temáticas atuais e os critérios de escolha, tal como elas apareceram em vários dos trabalhos de sistematização (Weissmann et al, 1992).

Nos últimos anos tem se incorporado alguns temas, tais como cinemâtica circular, dinâmica do corpo rígido e ondas, por serem considerados relevantes pela banca de professores que avalia no exame final, mas sua incorporação não recebeu outro tipo de justificativa para os docentes do TEF.

Tabela I

\begin{tabular}{||l|l||}
\hline \multicolumn{1}{|c|}{ UNIDADE } & \multicolumn{1}{|c|}{ CRITERIO DE SELEÇĀO E SEQÜENCIAÇĀO } \\
\hline \hline $\begin{array}{l}\text { Conceitos sobre } \\
\text { metodologia científica } \\
\text { prévios ao estudo da Física } \\
\text { no TEF }\end{array}$ & $\begin{array}{l}\text { Explicitação de uma linguagem compartilhada. Introdução à } \\
\text { metodologia científica segundo a visão do TEF. }\end{array}$ \\
\hline $\begin{array}{l}\text { Ferramentas matemáticas: } \\
\text { vetores, funções, derivada, } \\
\text { máximos e mínimos, } \\
\text { integrais. }\end{array}$ & $\begin{array}{l}\text { Estas ferramentas matemáticas são imprescindíveis no estudo da } \\
\text { Física e os alunos não as adquiriram previamente ou não sabem } \\
\text { "contextualizada". ấsica. Pretende-se ensinar a matemática }\end{array}$ \\
\hline Cinemâtica da partícula & $\begin{array}{l}\text { É a unidade mais apta pela sua simplicidade conceitual para aplicar e } \\
\text { transferir os conteúdos (conceituais e procedimentais, matemáticos e } \\
\text { metodológicos) trabalhados previamente e para definir uma linguagem } \\
\text { (por exemplo: "estado" do sistema de estudo) que sera utilisada ao } \\
\text { longo do curso todo. Contém conceitos estruturantes da Física (tal } \\
\text { como velocidade), necessários para o estudo de todas as teorias } \\
\text { físicas. Permite a relação com o mundo cotidiano. }\end{array}$ \\
\hline Dinâmica da partícula & $\begin{array}{l}\text { É um conteúdo estruturante da Física e permite compreender o que é } \\
\text { uma teoria para a Física (a Mecânica Clássica). É necessária para a } \\
\text { abordagem dos temas posteriores do curso e de grande utilidade nos } \\
\text { estudos biológicos e geológicos. }\end{array}$ \\
\hline Fluídos & $\begin{array}{l}\text { São conteúdos estruturantes da Física, úteis para biólogos e geólogos. } \\
\text { São necessários para o estudo da Termodinâmica e de quase todos os } \\
\text { temas da Física. }\end{array}$ \\
\hline Trabalho e & $\begin{array}{l}\text { É um conteúdo estruturante da relação entre a Física e a Biologia ou } \\
\text { Geologia. }\end{array}$ \\
\hline Energia & $\begin{array}{l}\text { É um conteúdo que permite abordar outro tipo de modelo, aplicável nas } \\
\text { Ciências Naturais. Permite a aplicação dos conhecimentos adquiridos. }\end{array}$ \\
\hline
\end{tabular}



X Modificações no conceito de avaliação e seu alcance. Incorporação da
autoavaliação.

Uma inovação em relação ao contexto universitário muito poderosa da proposta, tem sido a mudança no sistema de avaliação, por renovar-se ano a ano o "contrato de avaliação" com os alunos; propor-se aos alunos a realização de avaliações da atuação docente, e do TEF em geral; levar em conta para a avaliação os conteúdos conceituais, procedimentais e atitudinais; e discutir entre docentes e alunos as diferenças existentes entre avaliar e creditar (Ivancich et al, 1991 e 1993; Petrucci e Cordero, 1994).

Xesenvolvimento de uma atitude crítica frente à tarefa docente por parte do grupo de professores, e inclusão dos estudantes nesse processo, que se consolida em uma mudança do papel docente.

Reuniões de planejamento docente são realizadas semanalmente, com a participação horizontal de todos os membros da cátedra, e o convite à participação dos alunos, prática absolutamente incomun na universidade de um modo geral. Esse espaço, mais aqueles oferecidos durante o desenvolvimento das aulas e na avaliação, possibilita a discussão das atitudes docentes e a sua revisão permanente. A transferência da experiência a outros âmbitos, a sua sistematização, e as investigações realizadas acerca dela, também têm sido espaços de reflexão e revisão do papel docente.

\section{Realização de instâncias de capacitação pedagógica.}

Cientes das carências na sua formação para a prática docente - a equipe do TEF é constituída por físicos, biólogos, geólogos e estudantes dos Bacharelados nessas disciplinas - os professores têm procurado e gerado diversas oportunidades de capacitação pedagógica. Uma delas, a "Aula Paralela", objeto de análise de um trabalho específico (Cordero et al, 1997), é um espaço de reflexão sobre a prática docente, gerado pela equipe do TEF, que vem se desenvolvendo desde o início da experiência. Não são encontros regulares, mas criados nos momentos em que determinados problemas acontecem. Em geral são coordenados por especialistas convidados, e têm constituído situações para a reflexão e discussão sobre questões curriculares, grupais, institucionais, pessoais, etc., através de dinâmicas grupais e lúdicas.

X Tomada de consciência dos docentes do TEF de suas representações a respeito do papel docente, do modelo de aluno e do processo de ensinoaprendizagem.

A reflexão permanente sobre a prática, desenvolvida nas reuniões de planejamento, nas instâncias de capacitação, e na elaboração de produções de fundamentação e sistematização da experiência, tem tido efeitos "iluminadores" para os docentes em relação as suas concepções pedagógicas, levando-os a questioná-las e revisá-las.

\section{Desenvolvimento de ações de extensão a outros âmbitos universitários e não universitários.}


Desde o inicio da experiência, vêm se realizando tarefas de extensão nos mais diversos contextos, apresentando neles diferentes aspectos da proposta: estratégias de ensino, propostas de abordagem de conteúdos específicos, estratégias de trabalho em equipe, etc. Um espaço muito útil nesse sentido tem sido os cursos de formação contínua para professores de ciências naturais dos diferentes níveis de ensino, planejados e levados à prática por docentes do TEF e colaboradores.

\section{Vontade de sistematizar o estudo e pesquisa dos problemas relativos ao Ensino da Física.}

Numerosas publicações e apresentações em encontros científicos, escritas pelos docentes e colaboradores, que foram sendo citados ao longo deste artigo, foram fruto do TEF, analisando diferentes aspectos da proposta.

\section{A equipe de professores e suas formas de trabalho}

A equipe docente ${ }^{8}$ está constituída por professores graduados e estudantes de Física, Biologia e Geologia, conformando um grupo interdisciplinar que se renova ano a ano. $O$ número de docentes tem variado de um máximo de vinte trabalhando com diferentes "comissões" (grupos de alunos, com horários e espaços de trabalho independentes) a dez docentes para uma mesma "comissão". Como pode ser deduzido disto, ano a ano tem se experimentado distintas modalidades na organização dos recursos humanos, a fim de melhorar a relação docente-aluno e o trabalho na sala de aula. Atualmente, em função das atividades planejadas, alterna-se a divisão dos alunos (aproximadamente 200) em três comissões, ou seu agrupamento em uma mesma, trabalhando nela um grupo de quinze docentes.

No caso dos docentes que pertencem ao Departamento de Física, eles não realizam concurso para o preenchimento do cargo de uma disciplina em particular; eles fazem concurso para integrar o Departamento e, a cada ano, escolhem a matéria da qual desejam participar. Em geral, o TEF é escolhido pelos mesmos professores, mas todo ano ingressam novos assistentes, e outros docentes deixam o TEF para desenvolver atividades de pesquisa em suas disciplinas específicas. Isso gera uma dinâmica de ingressos e egressos permanentes, e a necessidade constante de formação e adaptação de novos docentes à modalidade de trabalho.

Essa modalidade de trabalho peculiar em relação ao contexto geral, caracteriza-se, entre outros aspectos, porque os integrantes da equipe docente desempenham as diversas atividades de ensino alternativamente, independendo da hierarquia acadêmica, mas de acordo com a capacidade que cada docente tem para a atividade planejada. As exposições teóricas, por exemplo, podem ser realizadas pelo Professor Titular, os Chefes de Trabalhos Práticos e/ou os Assistentes Diplomados com a formação física, biológica ou geológica necessária para o tema considerado ${ }^{9}$.

Por exemplo, nas aulas acompanhadas, como parte do trabalho de campo de uma das pesquisas realizadas no contexto do TEF (Cordero, 1999), ocorreu este modo diferente

\footnotetext{
${ }^{8}$ Uma característica organizativa da Universidade argentina é a existência da estrutura de cátedra, quer dizer que cada disciplina é ministrada por um conjunto/equipe de docentes. Dessa equipe participam também estudantes dos respectivos cursos, exercendo na maioria das cátedras funções parecidas com as do "monitor" na Universidade brasileira.

${ }^{9} \mathrm{Na}$ maioria das cátedras universitárias argentinas, apenas Professores Titulares, Associados ou Adjuntos desenvolvem as aulas teóricas.
} 
de organização do trabalho. Estas aulas foram planejadas por uma mini-equipe de três docentes (um Chefe de Trabalhos Práticos de formação biológica, um Assistente Diplomado, com formação física, e a colaboração parcial do outro Chefe de Trabalhos Práticos de formação física).

Tendo começado sua tarefa de preparo bem antes do período de aulas destinado à unidade pedagógica desse estudo, esses docentes iam apresentando os planos de aula, e discutindo as atividades, objetivos, conteúdos envolvidos, distribuição dos tempos, etc., com o resto da equipe, a cada reunião de planejamento. Esse espaço de discussão constituía a melhor solução para uma ação coordenada, e permitia revisar o acontecido a cada aula, a fim de ajustar as posteriores, tendo clareza sobre a atuação esperada para cada docente. Em função dessa primazia no preparo do tema (que em outras unidades pedagógicas passara para outras mini-equipes docentes) as exposições teóricas ("teóricos dialogados")também ficaram sob a responsabilidade desses professores, agindo os docentes restantes apenas como assistentes ou ouvintes atentos às falas e dúvidas que os alunos não tínham coragem de expressar à viva voz.

Durante os trabalhos grupais, cada grupo de alunos possuía dois ou três "referentes": docentes com distinta formação, responsáveis pelo acompanhamento do grupo e por manter um vínculo de proximidade, facilitador da aprendizagem. Esses professores alternavam funções em sua participação nos grupos, indo de "consultores" no esclarecimento das tarefas; "geradores" de questões para orientar a discussão; ou a "explicadores", que repetiam aquelas explicações não compreendidas a partir da exposição teórica geral; e "coordenadores" na discussão para a resolução de problemas; ou "administradores", indicando os tempos disponíveis e controlando a realização das atividades propostas.

Essa proximidade e avaliação permanente das compreensões alcançadas pelos alunos permitia um ajuste constante das aulas - realizado in situ a partir de breves discussões entre membros da equipe - introduzindo-se exposições e discussões gerais, quando os "referentes" as consideravam necessárias, ou variando a distribuição dos tempos destinados a cada tarefa.

As atitudes delineadas permitem-nos qualificar o pensamento docente, que guia 0 trabalho da equipe do TEF, como sendo complexo, estratégico e compreensivo:

"Entendemos como complexo aquele pensamento que trabalha sobre a incerteza, as noções de ordem e de desordem, que inclui o aleatório, o acaso, a totalidade como constituída por partes em um todo e um todo em partes, caracterizada pela diversidade e não pela uniformidade, pelas articulações e interações [...]

Estratégico, uma vez que trabalha sobre um cenário de ação, modificável, no qual o incerto e imprevisível têm lugar, portanto, não marca uma seqüência de atos, mas abre alternativas diversas de ação, inclui a abertura de possibilidades, probabilidades, adequando-se às situações ou cenários singulares.

Entendemos como compreensivo [...] um conhecimento que se abre ao social, é auto-reflexivo e crítico. Implica uma relação criativa, autônoma de conhecimento." (Souto, 1993:247. Tradução nossa)

Essas características manifestam-se nas alternativas de tarefas apresentadas aos alunos; na atenção constante ao percurso e à diversidade das compreensões alcançadas; na variação dos planos segundo essas compreensões; na discussão e reflexão constante da 
equipe docente; e nas atitudes de liberdade e criatividade (Gardner, 1995) com que os professores do TEF encaram seu trabalho cotidiano.

\section{Pressupostos pedagógicos}

Através da prática docente e as diversas situações de reflexão sobre ela, os professores do TEF chegaram a explicitar alguns de seus pressupostos pedagógicos. São esses pressupostos os que se manifestam no seu estilo de ensino que vínhamos caracterizando (Pacheco Schnetzler, 1992). Essas idéias, construídas coletivamente, nos surpreenderam em suas coincidências com resultados de diversas investigações recentes em educação em ciências.

De forma geral, pode-se dizer que o TEF sustenta uma postura plural a respeito da aprendizagem, do ensino e da relação docente-aluno.

Considera-se, por exemplo, que o papel do docente consiste em gerar situações, a partir de uma atitude crítica e criativa, que orientem o aluno na construção de significados. Nessa tarefa as atitudes docentes desejáveis são a autenticidade, o apreço, a aceitação, a confiança e a compreensão empática.

Acredita-se que o conhecimento deve ser construído pelo indivíduo, a partir das idéias que possui, baseadas na sua experiência com o mundo e com os outros. Pensa-se que essas idéias prévias, assim como as atitudes e os hábitos, se encontram fortemente estruturadas. Fala-se da aprendizagem como "evolução conceitual", pretendendo desta forma superar a concepção de substituição afirmada pela Teoria da Mudança Conceitual, e considerar a possibilidade da coexistência/convivência de conhecimentos alternativos e científicos.

A consecução da aprendizagem depende, para os docentes do TEF, de situações externas ao aluno (docentes, colegas, aulas, livros, experimentos, etc.) e de experiências, idéias prévias e atitudes respeito da aprendizagem e seu contexto. Outro condicionante do estilo da aprendizagem, segundo eles, é a concepção que os alunos sustentam acerca da avaliação (Petrucci e Cordero, 1994). Nesse sentido considera-se que um processo de avaliação controlado não apenas por docentes, mas também pelos próprios alunos, fortalece a responsabilidade individual a respeito da aprendizagem.

Finalmente, os docentes do TEF sustentam que o reconhecimento dos alunos como possuidores de um saber (não necessariamente científico, mas útil para sua evolução conceitual) e como seres co-responsáveis da avaliação (através do controle compartilhado do processo), favorece a modificação da distribuição do poder na sala de aula, tendendo à democratização das relações (Cordero et al, 1996).

\section{Reflexões finais}

Temos caracterizado a proposta pedagógica do TEF, descrevendo a experiência a partir de suas inovações mais relevantes, para depois analisar as formas de trabalho da equipe docente. Mas parece-nos importante ainda refletir a respeito de duas questões: quais as condições que consideramos necessárias para que uma equipe destas características poda se constituir e funcionar? E também: como pode ser explicada sua continuidade ao longo dos anos? Sem tentar responder de forma exaustiva estas perguntas, limitaremos-nos a comentar alguns elementos que pensamos imprescindíveis para que esse processo tenha acontecido. 
Faz 16 anos que a equipe docente do TEF vêm desenvolvendo um processo de inovações graduais, testando -e avaliando- alternativas que abarcam dimensões e aspectos variados. Neste trabalho, o pensamento da equipe docente foi qualificado como sendo complexo, estratégico e compreensivo. Essa caracterização, conjuntamente com a explicitação de suas inovacões, levam-nos a identificar a estes professores com aqueles descritos pelo paradigma emergente do docente artista-reflexivo:

“Obras já consideradas clássicas (Eisner, 1979) ajudam a elaborar o novo paradigma, no qual os professores são chamados de artistas-reflexivos (Pérez Gómez, 1992). Eisner assume que ensinar é uma arte porque uma aula, além de ser uma fonte de experiência estética, depende da percepção e do controle em ação de muitas variáveis, sendo uma atividade criativa e inovadora que não é dominada por prescripções. Para ele o ensino é um empreendimento no qual deve estar presente uma tensão entre automatiçações necessárias e invenções que surgem na ação. Isto o torna complexo, uma vez que ensinar requer rotinas com as quais trabalhar, para que a sua expressão artística ocorra. Tais rotinas ou repertórios de ensino possibilitam ao professor lidar inventivamente com o que ocorre na sala de aula, sendo impróprio supor que o campo das Belas Artes tenha o monopólio do uso de atividades expressivas, que causam surpresa e geram transformações nos alunos." (Queiroz, 2000:15)

Esse "controle em ação de muitas variáveis" supõe de parte dos docentes, uma visão da classe como um sistema complexo, um "laboratório", onde experimentar suas inovações didáticas. Nesse laboratório, o pesquisador não apenas não pode controlar todas as variáveis; ele não sabe se não está deixando sem considerar variáveis relevantes. Aceitando essa dificuldade como insuperável, como podem ser minimizados seus efeitos? Em início, os docentes devem ser conscientes desta complexidade. A seguir, uma multiplicidade de olhares melhora as possibilidades de considerar mais variáveis. Essa multiplicidade manifesta-se no TEF através de dois fatos. Por um lado os ex-alunos do TEF aportam um olhar próximo ao dos alunos. Por outro lado, o caráter interdisciplinar da equipe docente outorga também diferentes pontos de vista. A conformação de uma equipe desse tipo requer de uma atitude de respeito pelo outro e de vontade de compreender sua linguagem para poder se comunicar.

Outro elemento imprescindível relaciona-se com a visão de aluno que orienta à prática docente. Muitos professores caracterizam a seus alunos utilizando adjetivos negativos (Antelo, 1999). Essa imagem de aluno condiciona as propostas docentes que objetivam a motivação para a aprendizagem. Considerando impossível provocar motivações intrínsecas (inerentes à tarefa), opta-se por aquelas formas de motivação extrínsecas baseadas em mecanismos coercitivos (avaliações sumativas, sistemas de prêmios e castigos, etc.). No caso do TEF, uma equipe com o perfil já caracterizado, trabalha a partir da hipótese de que as atitudes negativas dos alunos em relação ao curso e a aprendizagem, são produto do contexto educativo e da história pessoal. Para superar essa situação os docentes do TEF tentam modificar esse contexto, necessidade considerada durante todas as intervenções. Até algumas intervenções apontam a trabalhar explícitamente sobre as atitudes dos alunos respeito do curso e da aprendizagem da física. Obtem-se desse modo um clima de trabalho agradável, caracterizado por motivações intrínsecas em relação à 
aprendizagem. Esse clima de trabalho agradável, ao nosso entender, permite desfrutar a tarefa docente, uma das chaves para explicar a continuidade da experiência.

O interesse e a paixão que gera trabalhar neste contexto, acrescentados pela obtenção de resultados positivos nas inovações, constituem incentivos, não apenas compensadores do esforço de cada inovação tentada, mas também para aprofundar a reflexão sobre a tarefa docente. Dita reflexão se concreta em numerosas investigações em educação em ciências, algumas das quais foram base do presente trabalho.

Finalmente queremos destacar que esse cíclico processo de inovação acorda em muitos dos novos integrantes uma grande vocação pela docência. As oportunidades de observar em ação a outros docentes e de realizar uma prática contínua, enriquecida pela crítica e as sugestões dos colegas mais experientes, fazem do TEF um valioso espaço de formação de professores. Isto possibilita a continuidade da experiência e sua transferência a outros âmbitos educativos.

\section{Agradecimentos}

Aos professores e alunos do TEF que ao longo dos anos permitiram e realizaram as diversas pesquisas base deste artigo. Ás professoras Dominique Colinvaux e Ana G. Dumrauf pela orientação da dissertação de Mestrado que foi origem desta apresentação. $E$ por último ás professoras Sonia Krapas e Maria Vera Vasconcelos que estimularam a elaboração deste trabalho. 


\section{REFERÊNCIAS BIBLIOGRÁFICAS:}

ANTELO, E. 1999. Instrucciones para ser profesor. (Buenos Aires: Ed. Santillana).

CAPPANNINI, O.M., LÚQUEZ, V., MENEGAZ, A., SEGOVIA, R., TITO, G. e VILLATE, G. 1996. Introducción de conceptos de metodología científica en un curso de física de grado. Memorias del III Simposio de Investigadores en Educación en Física, Córdoba, Argentina, 193-199.

CORDERO, S. 1999. Aprender com outros: Um estudo das interações entre alunos em aulas universitárias de física. Dissertação do Mestrado em Educação, Universidade Federal Fluminense.

CORDERO, S., PETRUCCI, D. e DUMRAUF, A. G. 1996. Enseñanza Universitária de Física: ¿En un Taller?. Revista de Enseñanza de la Física, 9 (1) 14-22.

CORDERO, S., PETRUCCI, D. e ROS, M. 1996. El "aula paralela": un espacio formativo para la reflexión sobre la práctica docente en física. Memorias del III Simposio de Investigadores en Educación en Física, Córdoba, Argentina, 431-432.

DRIVER, R. e OLDHAM, V. 1997. Un enfoque constructivista del desarrollo curricular en ciências. In: PORLÁN, R.; GARCÍA, E. \& CAÑAL, P. (orgs.) Constructivismo y Enseñanza de las ciencias. 113-134 (Sevilla: Díada).

DUMRAUF, A.G. 1997. Images of Science and Science Education: Discontent and Creativity in a case study for teaching physics. History, Philosophy and Science Teaching Conference, Calgary, Canadá.

DUMRAUF, A.G. 2001. "Esas otras cosas que se enseñan que no son física": Imágenes de ciencia y prácticas docentes en una experiencia universitaria de enseñanza de física. Investigaciones en Enseñanza de las Ciencias, 6 (1).

DUMRAUF, A. G., CORDERO, S. e COLINVAUX, D. 2000. Construyendo puentes y fronteras: Elementos para un análisis sobre género discursivo en una clase universitaria de física. Actas del V Simposio de Investigadores en Educación en Física, Santa Fe, Argentina.

EISNER, E. 1979. The Educational Imagination On the Design and Evaluation of School Programs. (N.York: Macmillan Publishing).

GARDNER, H. 1995. Mentes creativas. (Barcelona: Paidós).

IVANCICH, A., PETRUCCI, D. e MERCADER, R.C. 1991. Evaluar y evaluarnos... Enseñanza de las Ciencias, 9 (2) 211. 
IVANCICH, A.; PETRUCCI, D. e MERCADER, R.C. 1993. Un problema a resolver en un curso autogestionario: evaluación grupal. ContactoS, 8, 38-46.

KRASILCHIK, M. 1992. Caminhos do ensino de ciências no Brasil. Em Aberto, 11 (55), 3-8.

LIBEDINSKY, M. 2001. La innovación en la enseñanza. Diseño y documentación de experiencias de aula. (Buenos Aires: Paidós).

MELGAREJO, A., TITO, G. e CAPPANNINI, O. 1996. Propuesta para la enseñanza de la termodinámica del no equilibrio. Revista de Enseñanza de la Física, 9 (1), 29-36.

MOREIRA, M. A. 1996. Cambio conceptual: crítica a modelos actuales y una propuesta a la luz de la teoría del aprendizaje significativo. Memorias del III Simposio de Investigadores en Educación en Física, Córdoba, Argentina, 295-307.

PACHECO SCHNETZLER, R. 1992. Construção do conhecimento e ensino de ciências. Em Aberto, 11 (55), 17-22.

PEREZ GÓMEZ, A. 1992. O Pensamento Prático do Professor: A Formação do Professor como Profissional Reflexivo. Em: Os professores e a sua formação. Organizado por Nóvoa, A. (Lisboa: Publicações D. Quixote).

PETRUCCI, D. e CORDERO, S. 1994. El cambio en la concepción de evaluación. Implementación universitaria. Enseñanza de las Ciencias, 12 (2), 289-294.

POZO, J. I. y GÓMEZ CRESPO, M. A. 1998. Aprender y enseñar ciencia. (Madrid: Ed. Morata).

QUEIROZ G. R. 2000. Professores Artistas-Reflexivos De Física No Ensino Médio. Tese de Doutorado em Educação. Pontifícia Universidade Católica do Rio de Janeiro

PUIGGRÓS, A. 1993. Universidad, proyecto gneracional y el imaginario pedagógico. (Buenos Aires: Paidós).

SALINAS FERNÁNDEZ, D. 1994. Reflexión del profesor: la novedad de un viejo principio. Cuadernos de Pedagogía, 226, 81-87.

SCHON, D. 1995. Formar professores como profissionais reflexivos. NÓVOA, A. Os professores e a sua formação. (Lisboa: Pub. Dom Quixote).

SOUTO, M. 1993. Hacia una didáctica de lo grupal. (Buenos Aires: Miño y Dávila).

WEISSMANN, H., CORDERO, S., PETRUCCI, D., CAPPANNINI, O.M. e SEGOVIA, R. 1992. Informe final de sistematización. Presidencia de la Universidad Nacional de La Plata, Argentina. 
ZEICHNER, K. 1993. El maestro como profissional reflexivo. Cuadernos de Pedagogía, 220, 44-49.

Data da publicação: 26-02-02

Data da aprovação: 17-05-02 